\title{
Incremental shuttle walk test performed in a hallway and on a treadmill: are they interchangeable?
}

Shuttle walk teste incremental realizado no corredor e na esteira: eles são intercambiáveis? La prueba incremental Shuttle walk realizada en el pasillo y la cinta caminadora: $\dot{\text { son }}$ intercambiables?

\author{
Cristiane Santos de Oliveira', Anderson José', Crislaine Oliveira Santos', Cristiane Helga Yamane de \\ Oliveira', Thiago Cristiano Oliveira Carvalho', Jaksoel Cunha Silva', Jessyca Pachi Rodrigues Selman', \\ Rejane Agnelo Silva de Castro', Anderson Alves de Camargo', Simone Dal Corso'
}

\begin{abstract}
The performances of healthy individuals in an incremental shuttle walking test performed in a hallway (ISWT-H) and on a treadmill (ISWT-T) were compared to assess their physiological responses during aerobic training sessions with the speeds estimated from both tests. This was a cross-sectional study with 55 healthy subjects, who were randomized to perform the ISWT tests with 24 hours between them. Training sessions were held using a treadmill at $75 \%$ of the speeds obtained from the ISWT-H and ISWT-T. Measurements included walking distance, oxygen uptake $\left(\mathrm{VO}_{2}\right)$, carbon dioxide $\left(\mathrm{VCO}_{2}\right)$ production, heart rate (HR), and ventilation (VE). There was a significant

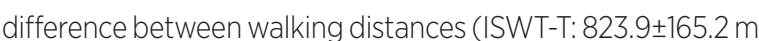
and ISWT-H:685.4 $\pm 141.4 \mathrm{~m}$ ), but similar physiological responses for $\mathrm{VO}_{2}\left(28.6 \pm 6.6 \mathrm{vs} .29 .0 \pm 7.3 \mathrm{ml}^{-1} \cdot \mathrm{kg}^{-1} \cdot \mathrm{min}^{-1}\right), \mathrm{VCO}_{2}$

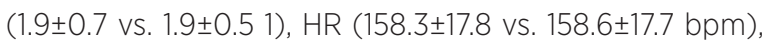
and VE (41.5 \pm 10.4 Vs. $43.7 \pm 12.9$ 1). The estimated speeds were different for the training sessions $(5.5 \pm 0.5 \mathrm{~km} / \mathrm{h}$ and $4.9 \pm 0.3 \mathrm{~km} / \mathrm{h}$ ), as well as the $\mathrm{VO}_{2}, \mathrm{VCO}_{2}, \mathrm{VE}$, and $\mathrm{HR}$. It was concluded that in healthy young adults, ISWTs carried out in a hallway and on a treadmill are not interchangeable. Since the ISWT-H was determined to have lower speed, the training intensity based on this test may underestimate a patient's responses to aerobic training.
\end{abstract}

Keywords I Exercise Test; Exercise; Walking; Oxygen Consumption.

RESUMO I Comparou-se o desempenho no shuttle walk teste incremental realizado no corredor (SWTI-C) e na esteira (SWTI-E) em indivíduos saudáveis e comparar as respostas fisiológicas durante as sessões de treinamento aeróbio com as velocidades estimadas em ambos os testes. Trata-se de um estudo transversal com cinquenta e cinco participantes saudáveis. Os participantes foram randomizados para realizar os testes com 24 horas de intervalo. As sessões de treinamento foram realizadas na esteira com 75\% da velocidade obtida no SWTI-C e no SWTI-E. As avaliações incluíram a distância da caminhada, consumo de oxigênio $\left(\mathrm{VO}_{2}\right)$, produção de dióxido de carbono $\left(\mathrm{VCO}_{2}\right)$, frequência cardíaca (FC) e ventilação (VE). Houve uma diferença significante entre as distâncias caminhadas (SWTI-E: 823,9 \pm 165,2 m e SWTI-C: 685,4 \pm 141,4 m), mas respostas fisiológicas semelhantes para o VO $\left(28,6 \pm 6,6\right.$ vs. $29,0 \pm 7,3 \mathrm{ml}^{-1} \cdot \mathrm{kg}^{-1}$. $\left.\min ^{-1}\right), V^{2} C_{2}(1,9 \pm 0,7$ vs. 1,9 $\pm 0,51), H R(158,3 \pm 17,8$ vs. $158,6 \pm 17,7 \mathrm{bpm})$ e VE (41,5 $\pm 10,4$ vs. $43,7 \pm 12,9$ 1). As velocidades estimadas foram diferentes para as sessões de treinamento $(5,5 \pm 0,5 \times \mathrm{km} / \mathrm{h}$ e 4,9 $\pm 0,3 \mathrm{~km} / \mathrm{h})$, assim como o $\mathrm{VO}_{2}, \mathrm{VCO}_{2}, \mathrm{VE}$ e FC. Concluiu-se que em adultos jovens saudáveis, SWTI realizados no corredor e na esteira não são intercambiáveis. Uma vez que o SWTI-E determinou uma menor velocidade, a intensidade do treinamento baseada neste teste pode subestimar as respostas de um paciente ao treinamento aeróbio.

Descritores I Teste de Esforço; Exercício; Caminhada; Consumo de Oxigênio.

RESUMEN I Se trata de una comparación del rendimiento en la prueba incremental shuttle walk llevado a cabo en el pasillo (SWPI-P) y en la cinta caminadora (SWPC) entre individuos sanos, para evaluar las respuestas fisiológicas durante las sesiones de entrenamiento aeróbico con 
velocidades estimadas en ambas pruebas. Estudio transversal con 55 individuos sanos. A los participantes se les eligieron al azar para realizar las pruebas con intervalo de 24 horas. Se llevaron a cabo sesiones de entrenamiento en la cinta caminadora con el $75 \%$ de la velocidad obtenida en SWPI-P y en SWPC. Se incluyen entre las evaluaciones la distancia de la caminata, el consumo de oxígeno $\left(\mathrm{VO}_{2}\right)$, la producción de dióxido de carbono $\left(\mathrm{VCO}_{2}\right)$, la frecuencia cardiaca (FC) y la ventilación (VE). Hubo una diferencia significativa entre las distancias recorridas (SWPC: 823,9 \pm 165,2 m y SWPI-P: 685,4 $\pm 141,4 \mathrm{~m}$ ), pero similares a las respuestas fisiológicas del VO $\left(28,6 \pm 6,6\right.$ vs. $\left.29,0 \pm 7,3 \mathrm{ml}^{-1} \cdot \mathrm{kg}^{-1} \cdot \mathrm{min}^{-1}\right), \mathrm{VCO}_{2}(1,9 \pm 0,7 \mathrm{vs}$. $\pm 1,90,51), \mathrm{HR}(158,3 \pm 17,8$ vs. $158,6 \pm 17,7 \mathrm{bpm})$ y $\mathrm{VE}(41,5 \pm 10,4 \mathrm{vs}$ $43,7 \pm 12,9$ 1). Las velocidades estimadas fueron diferentes en las sesiones de entrenamiento $(5,5 \pm 0,5 \mathrm{~km} / \mathrm{h}$ y 4,9 $\pm 0,3 \mathrm{~km} / \mathrm{h})$, así como $\mathrm{VO}_{2}, \mathrm{VCO}_{2}$, VE y FC. Se concluyó que, en los adultos jóvenes sanos, la SWPI Ilevada a cabo en el pasillo y en la cinta caminadora no pueden ser intercambiables. Dado que la SWPC determinó una menor velocidad, la intensidad de entrenamiento de esta prueba puede subestimar las respuestas de un paciente en el entrenamiento aeróbico.

Palabras clave I Prueba de Esfuerzo; Ejercicio; Caminata; Consumo de Oxígeno.

\section{INTRODUCTION}

The incremental shuttle walking test (ISWT) was designed to evaluate exercise capacity in patients with chronic pulmonary diseases ${ }^{1}$. The ISWT is a reproducible test with established reference values, and it is responsive to interventions ${ }^{2,3}$. In addition, previous studies have estimated the training intensity on a treadmill based on the peak speed reached during an ISWT ${ }^{4}$. However, a common disadvantage in relation to walking-based tests is the need for an appropriate physical space (10 $\mathrm{m}$ long in the case of the ISWT), which may not be available in hospitals, offices or clinics, or for patients receiving outpatient care. In addition, the need for continuous monitoring and oxygen supplementation in some of these patients makes performing the test difficult.

The six-minute walk test (6MWT) has similar limitations; for example, it requires a bigger hallway $(30 \mathrm{~m})^{2}$. To overcome this issue, the 6MWT has been performed on a treadmill; however, this strategy has led to a substantial decrease in walking distance ${ }^{5,6}$.One explanation for this finding was the time spent adjusting the speed of the treadmill ${ }^{6}$, since the rhythm of the $6 \mathrm{MWT}$ is selfpaced. It is possible that the ISWT, an externally-paced test, promotes similar walking distances and physiological responses when performed on a treadmill (ISWT-T) and in a hallway (ISWT-H). This assumption is based on a previous study that found no differences in walking distance, heart rate, dyspnea, or perception of effort when compared to the endurance shuttle walking test, another externally-paced test, performed on a treadmill and in a hallway ${ }^{7}$. Although some differences do occur in the patterns of muscle activation and joint movements between walking in a hallway and on a treadmill, the overall patterns of the two modes are fairly similar ${ }^{8}$, as is the energy expenditure 9

A few studies have compared the ISWT-H and the ISWT-T; however, their findings were controversial due to the small size of the samples of patients with cardiovascular disease $(n=8)^{10}$, post-myocardial infarction $(\mathrm{n}=10)^{9}$, and idiopathic pulmonary disease $(\mathrm{n}=19)^{11}$, which may have incurred a type-II error. Moreover, there have been no previous studies including patients with chronic pulmonary disease. Before considering this specific population, it was helpful to test the replacement of the hallway with the treadmill, and perform the ISWT in healthy subjects to evaluate the safety and concordance of their physiological responses during both tests. Then, these individuals were evaluated during physical training sessions based on the velocities obtained from the ISWT-H and ISWT-T.

Our hypothesis was that the performance of healthy subjects in the ISWT on a treadmill would be similar to their performance in the hallway. Therefore, the prescription of physical training through an ISWT-H or ISWT-T would result in similar cardiac demands, ventilatory demands, and metabolic loads. If proven, the hypothesis would show that a treadmill is a good alternative when an ISWT-H is not possible. Given the above, the aim of this study was to compare the safety, performance, and physiological responses of the ISWT-H and ISWT-T in healthy individuals, and to evaluate their acute physiological responses during training sessions with the intensities (speed percentages) determined by these two tests. 


\section{METHODOLOGY}

\section{Study design}

This was a cross-sectional study performed in two visits (24 hours apart). During the first visit, spirometry was performed, and each subject's body mass index (BMI) was calculated (weight/height $\left.{ }^{2}\right)^{12}$. The subjects were randomized to perform the ISWT-H or ISWT-T first. Thirty minutes after the ISWT-H or ISWT-T, a training session was held on a treadmill at $75 \%$ of the speed obtained from either the ISWT-H or ISWT-T (whichever one was performed that day). The flowchart of the selection of participants and the procedures are shown in Figure 1.

\section{Sample}

Through convenience sampling, 62 adult healthy individuals of both sexes, with normal lung function and a sedentary lifestyle (self-reported, individuals who performed physical activity less than $150 \mathrm{~min}$ per week having been considered as sedentary) were studied. Individuals with a history of smoking, neuromuscular or musculoskeletal diseases, cardiopulmonary disease, acute respiratory infection, or a BMI indicating obesity $\left(\mathrm{BMI} \geq 30 \mathrm{~kg} / \mathrm{m}^{2}\right)$ were excluded. This study was approved by the Local Research Ethics Committee (process number 418704), and all of the participants signed an informed consent form before the assessments.

\section{Assessments}

\section{Spirometry}

Spirometry was performed using an ULTIMA CPX (Medical Graphics, St. Paul, Minnesota, USA). The acceptability and reproducibility criteria adopted for the technical procedures were those recommended by the Brazilian guidelines for testing lung function ${ }^{13}$. The forced vital capacity (FVC), forced expiratory volume in the first second $\left(\mathrm{FEV}_{1}\right)$, and $\mathrm{FEV}_{1} / \mathrm{FVC}$ ratio were expressed in absolute values and as percentage of the predicted value for the Brazilian population ${ }^{14}$.

\section{Incremental shuttle walking test - hallway}

The ISWT-H was performed according to the original description $^{1}$ in a $10 \mathrm{~m}$-long hallway. This distance was marked by two cones that were placed $0.5 \mathrm{~m}$ from each edge. The individual followed this route at a predetermined speed imposed by an audible prerecorded rhythm. The ISWT was composed of 12 levels lasting one minute each, with an initial $0.5 \mathrm{~m} / \mathrm{s}$ speed and $0.17 \mathrm{~m} / \mathrm{s}$ increments each minute, reaching a maximum $2.37 \mathrm{~m} / \mathrm{s}$ speed. The test was interrupted if the individual did not successfully reach one of the cones at the time of the sound stimulus ( $0.5 \mathrm{~m}$ before the cone) twice. Other reasons for discontinuing the test were chest pain, intolerable dyspnea, leg cramps, staggering, diaphoresis, or a pale or ashen appearance ${ }^{2}$.

Heart rate (HR) (Polar Precision Performance; Polar Electro, Kem-skin, Finland) and oxygen pulse saturation (9500; Nonin, Plymouth, Minnesota, USA) were continuously measured during the test. The blood pressure and Borg Rating of Perceived Exertion for dyspnea and lower limb fatigue ${ }^{15}$ were obtained at rest and immediately after the end of the exercise. The walking distance was expressed as an absolute value and as percentage of the predicted value . $^{3}$.

\section{Incremental shuttle walking test - treadmill}

The ISWT-T was performed on a treadmill without incline (Millennium Classic; Inbrasport, Porto Alegre, $\mathrm{RS}$, Brazil) following the same protocol as the ISWT-H (above). The criterion for the interruption of the ISWT was a patient being $0.5 \mathrm{~m}$ from the cone at the time of the sound stimulus during two consecutive attempts. Then, a demarcation was established with masking tape fixed to the treadmill's bearing bar in parallel with the lower limb on each side of the treadmill for a similar test interruption parameter. In this context, the ISWT-T was interrupted if a patient did not keep the position of the lower limbs parallel to the masking tape two consecutive times during the sound stimulus. The handrail support was used by all subjects. The reasons for discontinuing the test were the same as those for the ISWT-H. The same variables described for the ISWT-H were measured during the ISWT-T.

\section{Aerobic training session}

A subgroup of 18 out of 55 participants selected through convenience sampling was evaluated to compare the acute physiological responses to the training sessions. For this test, the aerobic training speed was set to $75 \%$ of the maximum speed obtained from the ISWT-H or the ISWT-T ${ }^{16}$. The session lasted 20 minutes: 5 minutes of warm up (50\% of the target speed), 15 minutes at the target speed, and 5 minutes of slowdown. The handrail support was used by all subjects. The variables measured 
during the training session were the same as those measured during the ISWT-H and ISWT-T tests.

\section{Gas exchange analysis}

During the two tests and training sessions, a portable metabolic system (VO2000; Medical Graphics, St. Paul, MN, USA) was used to measure the oxygen uptake $\left(\mathrm{VO}_{2}\right)$, carbon dioxide production $\left(\mathrm{VCO}_{2}\right)$ and ventilation (VE). Before every test, a system calibration was performed according to the recommendations of the manufacturer. The measurements were taken at rest in the sitting position, throughout the entire test, and during the two-minute recovery period. For the metabolic and ventilatory analyses, the peak of the average of the test's last 30 seconds and the peak of the average of the training session's last three minutes were considered.

\section{Statistical analysis}

The data analysis was performed using the SPSS 20.0 software (SPSS, Chicago, Illinois, USA). The ShapiroWilk test was used to determine the normality of the data, and the data were expressed as means and standard deviations according to the adherence to the Gaussian curve. A Student's paired t-test was performed to compare the variables at the peak of the exercise between the two tests, and to compare the variables between the two training sessions. Comparisons of the $\mathrm{VO}_{2}, \mathrm{VE}$, and $\mathrm{HR}$ were performed every minute by using the analysis of variance (ANOVA) for repeated measures, with a post hoc Bonferroni analysis. The level of significance was $\mathrm{p}<0.05$, and effect size was calculated using Cohen's test. The statistical power of the sample size was calculated a posteriori using the $\mathrm{G}^{*}$ Power software (Universität Düsseldorf, Germany).

\section{RESULTS}

Sixty-two healthy subjects were recruited for this study. After seven exclusions, 55 subjects were surveyed (Figure 1). The baseline characteristics are shown in Table 1.

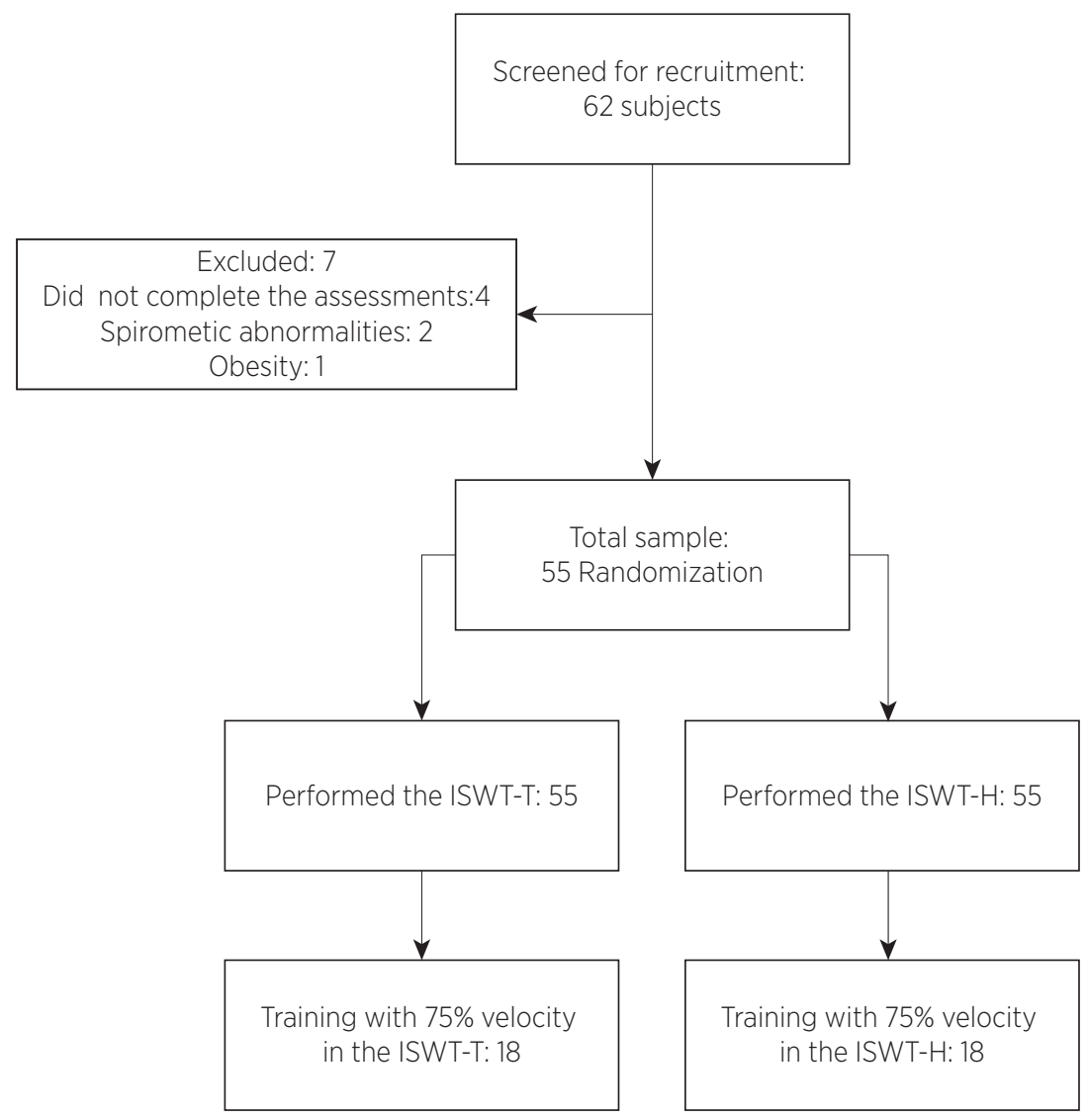

Figure 1. Flowchart of selection of participants and procedures 
Table 1. Baseline characteristics

$\begin{array}{lcc}\text { Variables } & \begin{array}{c}\text { ISWT Group } \\ \mathbf{n}=\mathbf{5 5}\end{array} & \begin{array}{c}\text { Training Group } \\ \mathbf{N}=\mathbf{1 8}\end{array} \\ \text { Age, years } & 24.8 \pm 8.3 & 25.3 \pm 12.7 \\ \text { Male/Female } & 26 / 29 & 4 / 14 \\ \text { Weight, } \mathrm{kg} & 64.5 \pm 10.9 & 58.9 \pm 7.9 \\ \text { Height, } \mathrm{m} & 1.7 \pm 0.1 & 1.6 \pm 0.7 \\ \text { Body Mass Index, } \mathrm{kg} / \mathrm{m}^{2} & 23.1 \pm 3.0 & 22.1 \pm 2.8 \\ \text { FVC, L } & 4.1 \pm 0.8 & 3.7 \pm 0.6 \\ \text { FVC, \% pred } & 97.6 \pm 13.6 & 98.3 \pm 9.4 \\ \text { FEV }, \text { L } & 3.5 \pm 0.7 & 3.2 \pm 0.7 \\ \text { FEV }, \% \text { pred } & 95.0 \pm 13.8 & 96.5 \pm 12.7 \\ \text { FEV, } / \text { FVC } & 0.9 \pm 0.1 & 0.7 \pm 0.1\end{array}$

ISWT: incremental shuttle walk test, $\mathrm{kg}$ : kilogram, m: meters, $\mathrm{kg} / \mathrm{m}^{2}$ : kilogram per square meter, FVC forced vital capacity, L: liters, \% pred: percentage predicted, FEV; forced expiratory volume in 1 second

A better performance (walking distance, speed, and test stage) was observed in the ISWT-T when compared to the ISWT-H (Table 2). For the distance walked, effect size was 0.89 and sample power was 0.99 . A higher $\mathrm{VO}_{2}(1 / \mathrm{min})$ also occurred in the ISWT-H when compared to the ISWT-T (Table 2). The performances at each stage of the ISWT-H and ISWT-T showed linear increases in $\mathrm{HR}, \mathrm{VO}_{2}$, and $\mathrm{VE}$ in both tests. The results showed significant differences between the two tests during the same stages of the ISWT: the $\mathrm{VO}_{2}$ of the $8^{\text {th }}$ stage, the ventilation of the $7^{\text {th }}$ stage, and the HR of the $10^{\text {th }}$ stage (Figure 2 ).

Table 2. Comparison between the cardiopulmonary variables at the end of the ISWT-H and of the ISWT-T

\begin{tabular}{|c|c|c|c|}
\hline \multirow{2}{*}{ Variables } & \multicolumn{3}{|c|}{$n=55$} \\
\hline & ISWT-H & ISWT-T & $P$ \\
\hline Distance, m & $685.4 \pm 141.4$ & $823.9 \pm 165.2$ & $<0.001$ \\
\hline Dist, \% pred & $60.1 \pm 8.9$ & $73.0 \pm 16.7$ & $<0.001$ \\
\hline Velocity, km/h & $6.8 \pm 0.7$ & $7.3 \pm 0.6$ & $<0.001$ \\
\hline Stages & $10.1 \pm 1.3$ & $10.9 \pm 1.1$ & $<0.001$ \\
\hline $\mathrm{HR}$, bpm & $158.3 \pm 17.7$ & $158.6 \pm 17.8$ & 0.88 \\
\hline HR, \% pred & $81.1 \pm 8.4$ & $81.2 \pm 8.6$ & 0.88 \\
\hline $\mathrm{SpO}_{2}, \%$ & $97.0 \pm 1.3$ & $97.2 \pm 1.0$ & 0.30 \\
\hline Borg dyspnea & $2.1 \pm 1.9$ & $1.8 \pm 1.7$ & 0.31 \\
\hline Borg lower limb & $2.9 \pm 2.5$ & $2.9 \pm 2.3$ & 0.88 \\
\hline $\mathrm{VO}_{2}, \mathrm{~L} / \mathrm{min}$ & $1.9 \pm 0.6$ & $1.8 \pm 0.5$ & 0.01 \\
\hline $\mathrm{VO}_{2}, \mathrm{ml} \mathrm{kg}^{-1} \mathrm{~min}^{-1}$ & $29.0 \pm 7.3$ & $28.6 \pm 6.6$ & 0.67 \\
\hline $\mathrm{VO}_{2}, \%$ pred & $81.2 \pm 13.9$ & $85.3 \pm 13.9$ & 0.79 \\
\hline $\mathrm{VCO}_{2}, \mathrm{~L}$ & $1.9 \pm 0.7$ & $1.9 \pm 0.5$ & 0.10 \\
\hline$R Q$ & $1.0 \pm 0.1$ & $1.0 \pm 0.1$ & 0.42 \\
\hline VE, L/min & $43.7 \pm 12.9$ & $41.5 \pm 10.4$ & 0.19 \\
\hline VE/MVV & $0.3 \pm 0.1$ & $0.3 \pm 0.1$ & 0.24 \\
\hline
\end{tabular}

ISWT-H: incremental shuttle walk test in hallway; ISWT-T: incremental shuttle walk test on treadmill; m: meters: \% pred: percentage predicted; HR: heart rate; bpm: beats per minute; $\mathrm{SpO}_{2} \%$ : pulse oxygen saturation; $\mathrm{VO}_{2}$ : oxygen uptake; $\mathrm{ml}^{.} \mathrm{kg}^{-1} \mathrm{~min}^{-1}$ : milliliters per kilogram per minute; L: liters; $\mathrm{VCO}_{2}$ : carbon dioxide production; VE: ventilation; L/min: liters per minute; VE/MVV: ventilation/ maximum voluntary ventilation; $R Q$ : respiratory quotient
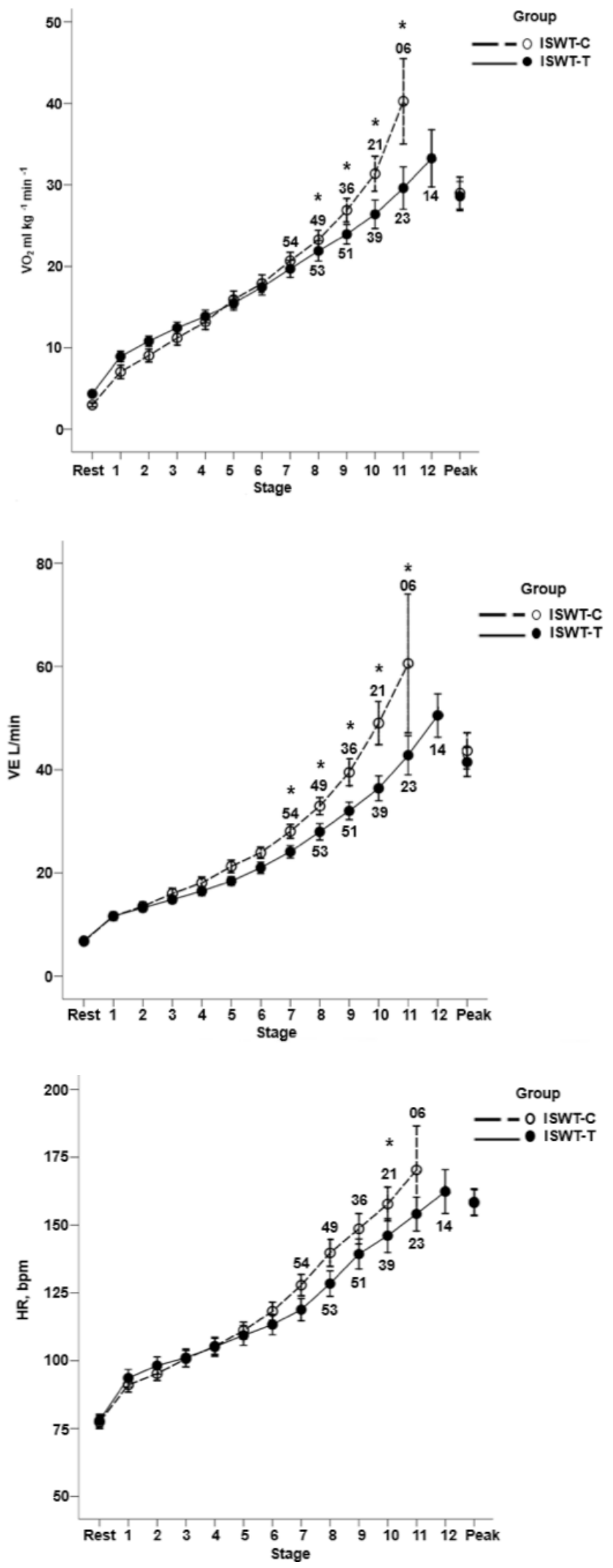

Values are expressed as mean and with 95\% confidence interval; ISWT-H: incremental shuttle walk test in hallway; ISWT-T: incremental shuttle walk test on treadmill (ISWT-T). N=55 until $7^{\text {th }}$ stage. *Significant difference between tests $(P<0.05)$

Figure 2. Oxygen consumption $\left(\mathrm{VO}_{2}, \mathrm{~A}\right)$, ventilation $(\mathrm{VE}, \mathrm{B})$ and heart rate (HR, C) per stage 
During the training sessions, significant differences in the metabolic, ventilatory, and cardiorespiratory responses were observed between the ISWT-T and ISWT-H. The percentages of the speeds determined from both tests was higher in the ISWT-T than in the ISWT-H, with 1.38 effect size and 1.0 sample power (Table 3 ). The changes in $\mathrm{VO}_{2}\left(\mathrm{ml} \mathrm{kg}^{-1} \cdot \mathrm{min}^{-1}\right)$ during each minute of the training session can be seen in Figure 3.

Table 3. Comparison between groups at the peak of the training session

\begin{tabular}{|c|c|c|c|}
\hline \multirow{2}{*}{ Variables } & \multicolumn{3}{|c|}{$\mathrm{N}=18$} \\
\hline & ISWT-H & ISWT-T & $\mathbf{P}$ \\
\hline Velocity $75 \%$ & $4.9 \pm 0.3$ & $5.5 \pm 0.5$ & $<0.001$ \\
\hline $\mathrm{VO}_{2} \mathrm{~L} / \mathrm{min}$ & $0.9 \pm 0.1$ & $0.9 \pm 0.2$ & 0.12 \\
\hline $\mathrm{VO}_{2} \mathrm{ml} \mathrm{kg}^{-1} \mathrm{~min}^{-1}$ & $14.9 \pm 2.5$ & $16.4 \pm 3.0$ & 0.008 \\
\hline $\mathrm{VO}_{2} \%$ pred & $44.4 \pm 8.8$ & $48.5 \pm 10.3$ & 0.008 \\
\hline $\mathrm{VCO}_{2}, \mathrm{~L}$ & $0.7 \pm 0.1$ & $0.8 \pm 0.1$ & 0.03 \\
\hline$R Q$ & $0.8 \pm 0.1$ & $0.9 \pm 0.1$ & 0.40 \\
\hline VE, L/min & $18.3 \pm 3.1$ & $20.2 \pm 4.1$ & 0.03 \\
\hline VE/MVV & $0.1 \pm 0.0$ & $0.2 \pm 0.5$ & 0.03 \\
\hline $\mathrm{HR}$, bpm & $110.3 \pm 11.7$ & $115.4 \pm 11.9$ & 0.04 \\
\hline HR, \% pred & $56.7 \pm 5.6$ & $59.5 \pm 6.5$ & 0.03 \\
\hline $\mathrm{SpO}_{2} \%$ & $97.4 \pm 1.4$ & $97.2 \pm 0.9$ & 0.45 \\
\hline Borg dyspnea & $0.3 \pm 0.5$ & $0.2 \pm 0.4$ & 0.75 \\
\hline Borg lower limb & $0.3 \pm 0.6$ & $0.4 \pm 0.5$ & 0.36 \\
\hline SBP, $\mathrm{mmHg}$ & $129.4 \pm 16.9$ & $125.6 \pm 12.5$ & 0.13 \\
\hline DBP, $\mathrm{mmHg}$ & $77.7 \pm 7.3$ & $76.1 \pm 6.9$ & 0.48 \\
\hline
\end{tabular}

ISWT-H: incremental shuttle walk test in hallway; ISWT-T: incremental shuttle walk test on treadmill; ml. $\mathrm{kg}^{-1} . \mathrm{min}^{-1}$ : milliliters per kilogram per minute; $\mathrm{VO}_{2}$ : oxygen uptake; \% pred: percentage predicted VE: ventilation; $L / m i n$ : liters per minute; $R Q$ : respiratory quotient; HR: heart rate; bpm: beats per minute; $\mathrm{SpO}_{2}$ : pulse oxygen saturation; SBP: systolic blood pressure; $\mathrm{mmHg}$ : millimeters per mercury; DBP: diastolic blood pressure

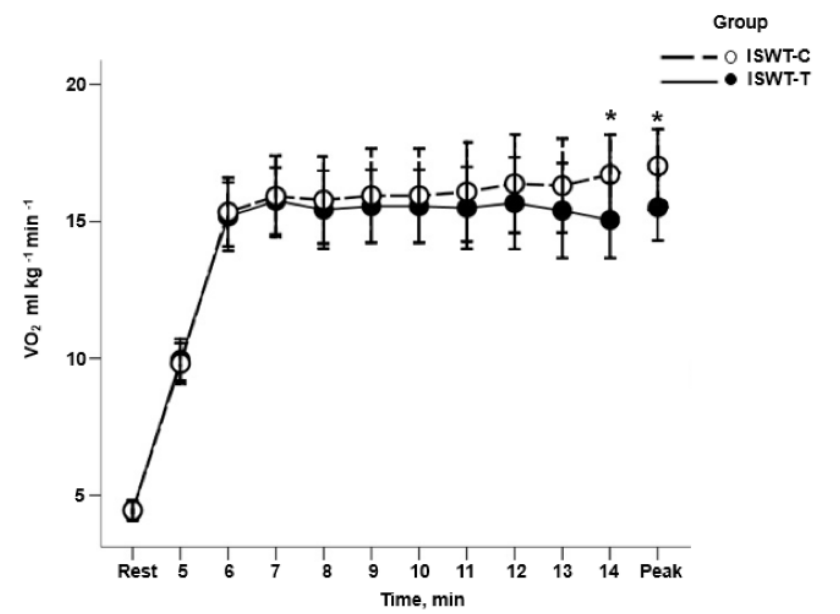

Values are expressed as mean and with $95 \%$ confidence interval. $n=18 .{ }^{*}$ Significant difference between tests $(P<0.05)$

Figure 3. Oxygen consumption $\left(\mathrm{VO}_{2} \mathrm{ml} \mathrm{kg}^{-1} \mathrm{~min}^{-1}\right)$ during training with loads obtained in the Incremental Shuttle Walk Test in Hallway (ISWT-H) and in the Incremental Shuttle Walk Test on Treadmill (ISWT-T)
Overall, the tests and the training sessions were safe for the participants. No adverse effects were observed during the procedures, and all of the subjects completed them without reporting any difficulties.

\section{DISCUSSION}

This study compared the cardiopulmonary and metabolic performance of healthy subjects during an ISWT-H and ISWT-T, and evaluated their physiological responses during aerobic training sessions with the intensities obtained from the ISWT-T and ISWT-H. The main findings of this study may be summarized as follows: (i) the ISWT-T showed greater walking distance and speed, but similar cardiorespiratory and metabolic demands in relation to the ISWT-H at the peaks of the tests; (ii) during the different stages of the ISWT, the ISWT-H showed superior demand $\left(\mathrm{VO}_{2}\right.$, VE, and HR) when compared to the ISWT-T in the $7^{\text {th }}$ stage; (iii) during the training session, greater metabolic and ventilatory requirements were observed with the speed obtained in the ISWT-T when compared to the ISWT-H; and (iv) performing the ISWT on a treadmill was a safe procedure. Considering these findings, we can say that the tests were not interchangeable, thus negating our hypothesis.

A substantial reduction in walking distance $\left[51.2 \pm 85.3 \mathrm{~m}^{6}\right.$ and $102 \mathrm{~m}(95 \% \mathrm{CI} 65-139)^{5}$ has been described when the $6 \mathrm{MWT}$ was performed on a treadmill. Additionally, when the $6 \mathrm{MWT}$ was performed on a non-motorized treadmill, the walking distance was even lower $(-153 \mathrm{~m})^{17}$. Similar results also occurred in the comparison between the 12-minute walk test in a hallway (12MWT-H) and on a treadmill (12MWT-T), with $82 \mathrm{~m}^{18}$ and $49 \mathrm{~m}^{19}$ differences between tests, respectively. One of the hypotheses for this finding is the lack of familiarity with the treadmill ${ }^{20}$. Therefore, conducting field tests on a treadmill has is recommended for the assessment of functional capacity ${ }^{20}$.

Some previous studies have compared the ISWT-H with the ISWT-T; however, the findings were controversial. For example, a pilot study with heart disease patients $(\mathrm{n}=8)$ showed a higher energy cost per meter, indirectly calculated, in the ISWT-T $(3.22 \pm 0.55 \mathrm{~J} / \mathrm{kg} / \mathrm{m})$ when compared to the ISWT-H $(3.00 \pm 0.41 \mathrm{~J} / \mathrm{kg} / \mathrm{m})$, but this pattern was reversed at $1.52 \mathrm{~m} / \mathrm{s}$ and $1.69 \mathrm{~m} / \mathrm{s}$ walking speeds when the shuttle walking test had a greater energy cost per meter than the treadmill walking test ${ }^{10}$. 
Thus, the metabolic cost of walking on a treadmill did not reflect that of walking on the ground ${ }^{10}$. Moreover, the current equations used to estimate the metabolic energy cost in the ISWT-H should not be applied when the ISWT is performed on a treadmill ${ }^{10}$. However, in a study with idiopathic pulmonary fibrosis patients $(\mathrm{n}=10)$, the ISWT-T showed better performance than the ISWT-H (mean difference: $43 \mathrm{~m})^{11}$, while the control group in another study with healthy subjects $(n=19)$ did not show differences in the energy expenditure between the ISWT-H and ISWT-T (mean difference: $-1.1 \pm 1.96$ METs $)^{9}$.It is possible that the small sample sizes of these studies may have caused a type-II error.

No differences were found in walking distance, $\mathrm{HR}$, dyspnea, or perception of effort when patients with chronic obstructive pulmonary disease (COPD) performed endurance tests with the same speeds on a treadmill and in a hallway ${ }^{7}$. However, during an incremental test, differences may occur between workloads that require increasingly greater effort, as demonstrated in our study. The physiological responses of the $\mathrm{VO}_{2}, \mathrm{VE}$, and $\mathrm{HR}$ began to show significant differences in the phases with an increased load when compared to the same iso stage (Figure 2). The same behavior has been shown in healthy subjects at higher speeds in the ISWT $(3 \mathrm{mph})^{9}$.

Contrary to a variety of studies ${ }^{5,6,10,18-19}$, better performance was found on the treadmill in our study. The demands were higher for the ISWT-H at the same stage (speed) as the ISWT-T, and the variables at the peak of the exercise were similar, despite the ISWT-T having resulted in greater walking distance and longer duration. We hypothesized that this was due to the arms being supported during the ISWT-T. It is known that the primary mechanism for balance maintenance during walking is the width of the step ${ }^{21}$ and the swinging of the $\operatorname{arms}^{22-23}$.With regard to the first mechanism, it has been shown that no differences exist in the intervals of time and the distance of the steps between walking in a hallway and on a treadmill ${ }^{19,24}$. However, eliminating the movement of the arms while walking results in a decrease in the interval between steps ${ }^{21}$, as does allowing the individuals to support themselves with their hands ${ }^{21,24}$. This support increases the side body balance during walking, reducing energy consumption and the demand required to maintain balance ${ }^{22-24}$. A similar effect occurs when manual support (using the hands) is allowed during step-based exercises, reducing $\mathrm{VO}_{2}$ and the $\mathrm{HR}^{25}$.

The role of the arms significantly affects the responses related to exertion while walking. Overall, allowing manual support reduces variability in the steps by $12 \%^{21}$, HR by $18 \mathrm{bpm}$, energy expenditure by $2.81 \mathrm{kcal} / \mathrm{min}$, perception of effort in the lower limb measured using the Borg scale by 1.92 points ${ }^{26}$ and $\mathrm{VO}_{2}$ expressed as $1 / \mathrm{min}$ by $0.175^{27}$ and as $\mathrm{ml} \cdot \mathrm{kg}^{-1} \cdot \mathrm{min}^{-1}$ by $7.75^{26}$. Due to this effect, and as demonstrated in our study, the exercise's maximum time duration is different, depending on whether the hands are or are not used for support $(9.9 \pm 4.1 \mathrm{~min} \text { vs } 8.0 \pm 2.9 \mathrm{~min})^{28}$.

The responses to exercise are also influenced by the intensity of the support provided by the hands. Significant differences exist when the hands are free and when they are used only as support (8.4\% reduction in the $\mathrm{VO}_{2}$ and $3.5 \%$ in the HR) versus when they are used with a strong grip (21\% reduction in the $\mathrm{VO}_{2}$ and $14.8 \%$ in the HR $)^{29}$. The same effect occurs in the perception of exertion, which decreases as the hands are free, with support and with a strong grip, respectively ${ }^{29}$. These findings are consistent with our study in which, although the maximum load achieved in the ISWT-T was greater, a similar perception of effort existed between the tests, because the support provided by the hands decreased this exertion.

Given these findings, the swinging of the arms and the support provided by the hands are important factors to consider during the evaluation and prescription of exercise on a treadmill ${ }^{22,23}$, demonstrating the need to standardize the position of the hands during prescription exercises, or to study the comparative effects of this support after the interventions ${ }^{27,28,30}$.

As expected, our study demonstrated that during training, the cardiorespiratory and metabolic demands were higher with the load obtained by the ISWT-T; therefore, if the training intensity on the treadmill is estimated from the ISWT-H, the aerobic training is possibly being underestimated. However, even using the workload determined by the ISWT-T, the training intensity corresponded to $59.5 \%$ of the maximum HR predicted, reinforcing sub-training. The greatest benefits obtained by aerobic training are related to training intensity (moderate-to-intense), which is directly related to better improvement in the exercise capacity and a reduction of symptoms in individuals with chronic diseases ${ }^{31}$.

\section{Study limitations}

The ISWT-T was conducted while allowing the use of the hands for support, which was relevant in changing the responses to the exercise. However, all of the participants underwent the same protocol, allowing the conclusions of this study to be valid for these tests, given that they 
were performed in the same way. Considering that the responses to training were underestimated, we could have used the modified ISWT, which allows running, but the objective of this study was to compare the classic protocols of the ISWT, which was developed for patients with chronic lung diseases. Finally, another limitation of the study is its convenience sample; however, the a posteriori statistical power showed a sample power higher than $80 \%$.

\section{CONCLUSION}

The performances of healthy young adults in ISWTs carried out in a hallway and on a treadmill are not interchangeable. Since the ISWT-H was determined to have lower speed, the training intensity based on this test may underestimate a patient's responses to aerobic training.

\section{REFERENCES}

1. Parreira VF, Janaudis-Ferreira T, Evans RA, Mathur S, Goldstein RS, Brooks D. Measurement properties of the incremental shuttle walk test: a systematic review. Chest. 2014;145(6):1357-69. doi:10.1378/chest.13-2071

2. Holland AE, Spruit MA, Singh SJ. How to carry out a field walking test in chronic respiratory disease. Breathe (Sheff). 2015;11(2):128-39. doi:10.1183/20734735.021314

3. Probst VS, Hernandes NA, Teixeira DC, Felcar JM, Mesquita RB, Gonçalves CG, et al. Reference values for the incremental shuttle walking test. Respir Med. 2012;106:243-8. doi:10.1016/j.rmed.2011.07.023

4. Lee AL, Hill CJ, Cecins N, Jenkins S, McDonald CF, Burge AT, et al. The short and long term effects of exercise training in non-cystic fibrosis bronchiectasis: a randomised controlled trial. Respir Res. 2014;15:44. doi:10.1186/1465-9921-15-44

5. De Almeida FG, Victor EG, Rizzo JA. Hallway versus treadmill 6-minute-walk tests in patients with chronic obstructive pulmonary disease. Respir Care. 2009;54(12):1712-6.

6. Stevens D, Elpern E, Sharma K, Szidon P, Ankin M. Comparison of hallway and treadmill six-minute walk tests. Am J Respir Crit Care Med. 1999;160(5Pt1):1540-3. doi:10.1164/ajrccm.160.5.9808139

7. Revill SM, Morgan MD, Singh SJ, Williams J, Hardman AE. The endurance shuttle walk: a new field test for the assessment of endurance capacity in chronic obstructive pulmonary disease. Thorax. 1999;54(3):213-22. doi:10.1136/thx.54.3.213.

8. Fukuchi CA, Fukuchi RK, Duarte M. A public dataset of overground and treadmill walking kinematics and kinetics in healthy individuals. Peer J. 2018;6:e4640. doi:10.7717/peerj.4640.

9. Woolf-May K, Ferrett D. Metabolic equivalents during the 10-m shuttle walking test for post-myocardial infarction patients. Br J Sports Med. 2008;42(1):36-41.
10 Almodhy M, Beneke R, Cardoso F, Taylor MJ, Sandercock GR. Pilot investigation of the oxygen demands and metabolic cost of incremental shuttle walking and treadmill walking in patients with cardiovascular disease. BMJ. 2014;16(4):e005216. doi:10.1136/bmjopen-2014-005216

11. Moloney ED, Clayton N, Mukherjee DK, Gallagher CG, Egan JJ. The shuttle walk exercise test in idiopathic pulmonary fibrosis. Resp Med. 2003;97(6):682-7. doi:10.1053/rmed.2003.1501

12. WHO Expert. Committee physical status: the use and interpretation of anthropometry. World Health Organ Tech Rep Ser. 1995;854:1-452.

13. Sociedade Brasileira de Pneumologia. Diretrizes para testes da função pulmonar. J Pneumol. 2002;28(Supl.3):S44-S58.

14. Rufino R, Costa CH, Lopes AJ, Maiworm Al, Maynard K, Silva LM, et al. Spirometry reference values in the Brazilian population. Braz J Med Biol Res. 2017;50(3):e5700. doi:10.1590/1414-431X20175700

15. da Silva CA, Helal L, da Silva RP, Belli KC, Umpierre D, Stein R. Association of lower limb compression garments during high-intensity exercise with performance and physiological responses: a systematic review and meta-analysis. Sports Med. 2018;48:1859-73. doi: 10.1007/s40279-018-0927-z

16. Spruit MA, Singh SJ, Garvey C, ZuWallack R, Nici L, Rochester C, et al. An official American Thoracic Society/European Respiratory Society Statement: key concepts and advances in pulmonary rehabilitation. Am J Respir Crit Care Med. 2013;188(8):e13-e64. doi: \10.1164/rccm.201309-1634ST

17. Janaudis-Ferreira T, Sundelin G, Wadell K. Comparison of the 6-minute walk distance test performed on a non-motorised treadmill and in a corridor in healthy elderly subjects. Physiotherapy. 2010;96(3):234-9. doi:10.1016/j.physio.2009.11.015

18. Swerts PM, Mostert R, Wouters EF. Comparison of corridor and treadmill walking in patients with severe chronic obstructive pulmonary disease. Phys Ther. 1990;70(7):439-42.

19. Beaumont A, Cockcroft A, Guz A. A self paced treadmill walking test for breathless patients. Thorax. 1985;40(6):459-64.

20. Holland AE, Spruit MA, Troosters T, Puhan MA, Pepin V, Saey D, et al. An official European Respiratory Society/American Thoracic Society technical standard: field walking tests in chronic respiratory disease. Eur Respir J. 2014;44(6):1428-46. doi:10.1183/09031936.00150314

21. Arellano CJ, Kram R. The energetic cost of maintaining lateral balance during human running. J Appl Physiol. 2011;112(3):427-34. doi:10.1152/japplphysiol.00554.2011.

22. ljmker T, Houdijk H, Lamoth CJ, Beek PJ, van der Woude LH. Energy cost of balance control during walking decreases with external stabilizer stiffness independent of walking speed. J Biomech. 2013;46(13):2109-14. doi:10.1016/j.jbiomech.2013.07.005

23. Meyns P, Bruijn SM, Duysens J. The how and why of arm swing during human walking. Gait Posture. 2013;38(4):555-62. doi:10.1016/j.gaitpost.2013.02.006

24. Yentes JM, Denton W, McCamley J, Raffalt PC, Schmid KK. Effect of parameter selection on entropy calculation for long walking trials. Gait Posture. 2018;60:128-34. doi:10.1016/j.gaitpost.2017.11.023

25. Berling J, Foster C, Gibson M, Doberstein S, Porcari J. The effect of handrail support on oxygen uptake during steady-state treadmill exercise. J Cardiopulm Rehabil. 2006;26(6):391-4. 
26. Hoffmann CL, Dougherty C, Abkarian HK, Fox M, Juris PM. The reduction of metabolic cost while using handrail support during inclined treadmill walking is dependent on the handrail use instruction. Int J Exerc Sci. 2014;7(4):339-45.

27. Foster C, Crowe AJ, Daines E, Dumit M, Green MA, Lettau S, et al. Predicting functional capacity during treadmill testing independent of exercise protocol. Med Sci Sports Exerc. 1996;28(6):752-6.

28. McConnell T, Foster C, Conlin N, Thompson N. Prediction of functional capacity during treadmill testing: effect of handrail support. J Cardiopulm Rehabil. 1991;11:255-60. doi:10.1249/00005768-198004001-00318

29. Berling J, Foster C, Gibson M, Doberstein S, Porcari J. The effect of handrail support on oxygen uptake during steady state treadmill exercise. J Cardiopulm Rehabil. 2006;26(6):391-4.

30. Wicks JR, Oldridge NB. How accurate is the prediction of maximal oxygen uptake with treadmill testing? PLoS One. 2016;11:e0166608. doi:10.1371/journal.pone.0166608 